\title{
Cidadania eTICs: uma relação anacrônica? ${ }^{1}$
}

\author{
Citizenship and TICs: an anachronistic relationship?
}

Ciudadanía y TICs: una relación anacrónica?

Marcos Marinho M. Queiroz ${ }^{2}$

Magno Medeiros ${ }^{3}$

\section{Resumo}

Este artigo tem como proposta inicial realizar um levantamento conceitual sobre cidadania, bem como uma análise da evolução das Tecnologias da Informação e Comunicação (TICs) e suas potenciais utilizações no tocante a otimizar o processo de apropriação desta cidadania por parte dos indivíduos viventes na polis. Por meio de uma pesquisa guiada pelo método de revisão bibliográfica aliou-se conceitos clássicos e modernos sobre a temática em questão, plotando-os na realidade hodierna em que a tecnologia atua fortemente nos processos de significação e ressignificação do status do cidadão e da própria cidadania, tema desta pesquisa. De posse dos conceitos e da análise contextual da relação TIC's - Cidadania alcançou-se, neste estudo, uma perspectiva de desnivelamento entre ambos, onde o anacronismo se faz presente e exige medidas que sejam capazes de corrigir tal assincronicidade. Por fim o presente texto reforça a necessidade de se repensar o processo educacional vigente nesta sociedade, a fim de que os indivíduos sejam preparados para dominar as tecnologias em busca de alcançar a condição de cidadão.

Palavras chave: Cidadania. TICs. Internet.

\begin{abstract}
This article's initial proposal to perform a conceptual survey of citizenship, as well as an analysis of the evolution of Information and Communication Technologies (ICTs) and their potential uses with regard to optimize the process of appropriation of this citizenship by living individuals in the polis. Through a survey led by the literature review method has teamed up classic and modern concepts on the subject in question, plotting them in today's reality in which technology has a strong presence in the processes of meaning and redefinition of citizen's status and citizenship itself, theme of this research. Possession of concepts and contextual analysis of the ICT - Citizenship is reached, in this study, a depression of perspective between them, where the anachronism is present and requires measures to be able to correct such asynchronicity. Finally this text reinforces the need to rethink the current educational process in this society, so that individuals are prepared to master the technology in search of reaching the citizen condition.
\end{abstract}

Key Words: Citizenship. TICs. Internet.

\footnotetext{
${ }^{1}$ Este trabalho foi desenvolvido dentro do Projeto de Pesquisa Rupturas Metodológicas para uma leitura crítica da Mídia entre os Programas de Pós-Graduação da UFG e UFRJ, que integra a ação transversal nº 06/2011 - Casadinho/Procad.

${ }^{2}$ Mestrando no Programa de Pós-graduação em Comunicação da Universidade Federal de Goiás (PPGCOM/UFG). Professor no curso de graduação em Publicidade e Propaganda na Universidade Federal de Goiás (UFG) e na Pontifícia Universidade Católica de Goiás (PUC-GO). E-mail: marcos@mmarinhomkt.com.br.

${ }^{3}$ Doutor em Educação pela Universidade de São Paulo (USP). Professor associado da Universidade Federal de Goiás (UFG), Faculdade de Informação e Comunicação (FIC). E-mail: magno.ufg@gmail.com.
}

Comun. \& Inf., Goiânia, GO, v. 18, n. 02, p. 163-179, jul./dez. 2015 


\section{Resumen}

La propuesta inicial de este artículo para realizar un estudio conceptual de la ciudadanía, así como un análisis de la evolución de las Tecnologías de la Información y la Comunicación (TIC) y sus usos potenciales en cuanto a optimizar el proceso de apropiación de esta ciudadanía por las personas que viven en la polis. A través de una encuesta dirigida por el método de revisión de la literatura se ha asociado conceptos clásicos y modernos sobre el tema en cuestión, el trazado en la realidad de hoy en el que la tecnología tiene una fuerte presencia en los procesos de significación y la redefinición de la situación y la ciudadanía misma del ciudadano, tema de esta investigación. Se llega a la Ciudadanía, en este estudio, una depresión de la perspectiva entre ambos, donde el anacronismo está presente y requiere medidas para poder corregir tales asincronía - La posesión de conceptos y análisis contextual de las TIC. Finalmente este texto refuerza la necesidad de repensar el proceso educativo actual en esta sociedad, por lo que los individuos están preparados para dominar la tecnología en busca de alcanzar la condición de ciudadano.

Palabras clave: Ciudadanía. TIC. Internet.

\section{INTRODUÇÃO}

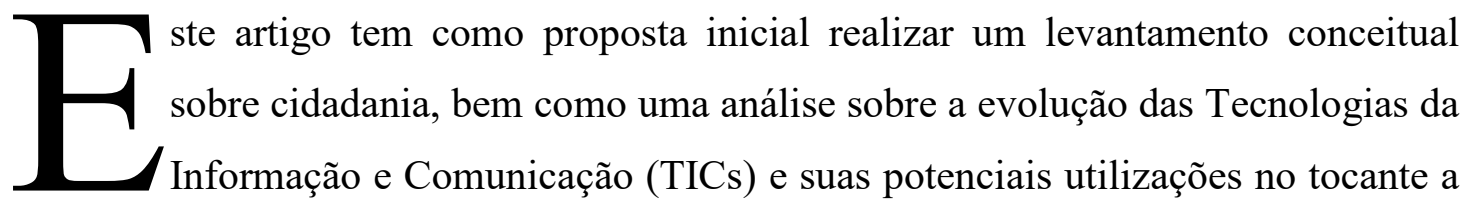
otimizar o processo de apropriação da cidadania por parte dos indivíduos viventes na polis.

Partiremos da premissa de que não é possível exercitar, em sua plenitude, algo com que não se está completamente familiarizado, o que gera, provavelmente, a figura do subcidadão. Essa observação é feita após constatarmos, por meio de revisão bibliográfica, os conceitos cunhados sobre cidadania e subcidadania e confrontá-los com o que pudemos observar cotidianamente através de recortes midiáticos e pesquisas acadêmicas. É possível que após este processo nos fique claro que a realidade das sociedades está bastante distante daquilo que os autores preconizam para o reconhecimento do status de cidadão.

No segundo momento trabalharemos com autores que investigam as novas tecnologias da informação e comunicação, sua utilização pelos indivíduos, seu potencial e sua acessibilidade por parte da sociedade. Neste momento serão abordadas expectativas, constatações e perspectivas em certo nível até conflitantes, mas que fornecerão subsídios para a verificação do potencial das novas ferramentas para a conquista da cidadania para todos.

Enquanto revisão bibliográfica este artigo aspira contribuir para o vanço dos estudos que relacionam cidadania e tecnologia da informação e comunicção com a evolução das sociedades e suas formas de apropriação da cidadania. 


\section{A CIDADANIA DE QUE NOS FALAM}

Falar sobre cidadania é percorrer vários caminhos que levam, aparentemente, a um mesmo destino, um status capaz de parametrizar e resguardar a condição do indivíduo no convívio dentro da polis, em sua sociedade de pertença. Compreendendo não ser possível uma experienciação plena da cidadania sem que haja amplo conhecimento dos seus significados, partiremos para o levantamento conceitual e contextual do que pode de fato estar abarcado neste mote.

A partir da constituição das cidades, podemos inferir, deu-se também a fundação das crises e dos conflitos sociais entre seus "cidadãos". Este entendimento apoia-se no pensamento hobbesiano sobre a natureza desejante do homem, que lhe põe a disputar com outro homem aquilo que lhe é objeto de desejo. Desta forma, e seguindo os contratualista, Ribeiro (2006) acreditava que somente a instituição e aceitação de um pacto social poderiam garantir a manutenção da vida em sociedade. Segundo Ribeiro (2006),

(...) o homem hobbesiano não é então um homo economicus, porque seu maior interesse não está em produzir riquezas, nem mesmo em pilha-las. $\mathrm{O}$ mais importante para ele é ter os sinais de honra, entre os quais se inclui a própria riqueza (mais como meio, do que como fim em si). Quer dizer que o homem vive basicamente de imaginação. Ele imagina ter um poder, imagina ser respeitado - ou ofendido - pelos semelhantes, imagina o que o outro vai fazer. Da imaginação - e neste ponto Hobbes concorda com muitos pensadores do século XVII e XVIII - decorrem perigos, porque o homem se põe a fantasiar o que é irreal. O estado de natureza é uma condição de guerra, porque cada um se imagina (com razão ou sem) poderoso, perseguido, traído (RIBEIRO, 2006, p. 61).

A coexistência coletiva, então, demanda claramente algum tipo de normativa que evite o "estado de guerra". Desta forma, pensar cidadania também corresponde a pensar as parametrizações de direitos e deveres que, até em nível coercitivo, impedirão que os desejos individuais dissolvam o Estado pensado para a promoção do bem comum, por ser este o alicerce da própria comunidade. Vale lembrar que, além da instituição das normativas, é fundamental que exista o conhecimento pleno dos temas concernentes à cidadania - direitos e deveres - por todos que por eles serão impactados.

Seguindo por outro caminho, temos que Carvalho (2002) enxerga a cidadania como sendo uma somatória dos direitos civil, político e social. $\mathrm{O}$ autor acredita que a própria sequência de consecução e formas de apropriação destes diretos influenciam sobremaneira no 
modo como a sociedade os acolherá e os significará, o que também interferirá no próprio comportamento social dos indivíduos.

Uma concepção que coaduna com a de Carvalho (2002) é apresentada por Meksenas (2002), quando este diz que:

$\mathrm{Na}$ origem, portanto, o conceito simboliza a igualdade jurídica entre os indivíduos e o fim dos privilégios legados pelo Absolutismo com a subordinação do governo à soberania popular. Em princípio, a cidadania confunde-se com os direitos contratuais que o povo estabelece com o Estado, devendo este último ser o seu representante legítimo (MEKSENAS, 2002, p.21).

Ambos autores creditam ao ambiente jurídico a legitimação da cidadania, reforçando que os direitos civis, políticos e sociais, pactuados em contratos celebrados entre a sociedade e o Estado garantiriam a todos, simplesmente por estarem previstos na legislação em vigor, a condição de cidadão, tornando-os efetivamente iguais perante a lei.

Adotamos ainda a fala de Marshall, a fim de reforçar a definição clássica de cidadania como “[...] um status concedido àqueles que são membros de uma comunidade. Todos aqueles que possuem o status são iguais com respeito aos direitos e obrigações pertinentes ao status". (MARSHALL, 1967, p.76). Aqui podemos perceber que o autor considera o sentimento de pertença imbricado no fato de estar presente o indivíduo no contexto social. Marshall (1967) também aponta que a cidadania é permeada por responsabilidades atinentes ao cidadão, o qual deve respeitar e cumprir normativas que promovem a manutenção do conjunto social.

Em linhas gerais, observamos que o conceito de cidadania está arraigado no empoderamento dos indivíduos que acessam direitos civis, políticos e sociais, e também se ocupam de deveres em relação à coletividade. Em uma perspectiva jurídica, a posse desses direitos é igualitária entre os pertencentes ao coletivo de viventes de determinada polis.

Por outro viés, segue o argentino Canclini (2008), que rompe com o aspecto jurídico da definição do ser cidadão e afirma que:

[...] ser cidadão não tem a ver apenas com os direitos reconhecidos pelos aparelhos estatais para os que nasceram em um território, mas também com as práticas sociais e culturais que dão sentido de pertencimento, e fazem que se sintam diferentes os que possuem mesma língua, formas semelhantes de organização e de satisfação de necessidades (CANCLINI, 2008, p.35).

Canclini (2008) vai além dos direitos aqui já citados como garantidores de cidadania e apresenta uma multiplicidade de fatores que devem ser considerados prementes para que haja 
real horizontalização do termo, como cultura, raça, gênero e até consumo. Este último, na visão do autor, está pari passu com o desenvolvimento dos meios de comunicação.

Não foram tanto as revoluções sociais, nem o estudo das culturas populares, nem a sensibilidade excepcional de alguns movimentos alternativos na política e na arte, quanto o crescimento vertiginoso das tecnologias audiovisuais de comunicação, o que tornou patente como vinha mudando desde o século passado o desenvolvimento do público e o exercício da cidadania. Mas esses meios eletrônicos que fizeram irromper as massas populares na esfera pública foram deslocando o desempenho da cidadania em direção às práticas de consumo (CANCLINI, 2008, p.38).

Diferentemente dos direitos defendidos pelos autores supracitados, que ancoram-se na discussão sobre o fato normativo-legal como igualitários - ainda que teoricamente - e por isso garantidores de uma isonômica cidadania, Canclini (2008) apresenta a imbricação do consumo como direito acessório, mas não menos importante, principalmente em países capitalistas de cultura neoliberal, que não encontram nas estruturas estatais geralmente qualquer garantia de acesso irrestrito para todos aqueles que partilham a cidade.

Em contraste com a noção jurídica de cidadania, que os Estados tentam delimitar sobre a base de uma "mesmice", desenvolvem-se formas heterogêneas de pertencimento, cujas redes se entrelaçam com as do consumo: "um espaço de lutas, um terreno de memórias diferentes e um encontro de vozes desiguais" (CANCLINI, 2008, p. 47).

Quando observamos de diferentes ângulos a cidadania, confrontando os aspectos jurídicos trabalhados por Carvalho (2002), Meksenas (2002) e Marshall (1967), com o entendimento de Canclini (2008), que se volta para questões econômico-sociais e, até, culturais, fica-nos difícil adotar uma única perspectiva sobre o tema. A complexidade que abarca o sentimento do indivíduo em relação ao seu pertencimento ao coletivo e, assim, sua forma de atuação e participação social possivelmente orientará sua conduta cotidiana e lhe oferecerá situações onde seu próprio entendimento em relação à sua cidadania poderão ser objeto de autoquestionamento.

Ainda sob o eco dos apontamentos de Canclini (2008), quando este enreda a cidadania nas malhas da comunicação, percebemos que há grande possibilidade de surgirem das tecnologias da informação e comunicação (TICs) as formas como as sociedades alcançarão a apropriação individual e coletiva - talvez com maior nível de paridade - da cidadania.

Podendo ser observados como mecanismos que ampliaram a exposição e, talvez, o debate sobre os assuntos da polis, os veículos de mídia de massa passaram a reconfigurar os espaços políticos e, em boa medida, os políticos e seus discursos. Muito além de meros

Comun. \& Inf., Goiânia, GO, v. 18, n. 02, p. 163-179, jul./dez. 2015 
expositores dos acontecimentos, os meios de comunicação se configuraram em participantes do contexto social, capazes até mesmo de, através de suas formas de edição e "interação", ocupar espaços anteriormente destinados ao Estado e seus representantes nas relações com os cidadãos. Sobre isso, Canclini (2008) rememora que

Não foram tanto as revoluções sociais, nem o estudo das culturas populares, nem a sensibilidade excepcional de alguns movimentos alternativos na política e na arte, quanto o crescimento vertiginoso das tecnologias audiovisuais da comunicação, o que tornou patente como vinha mudando desde o século passado o desenvolvimento do público e o exercício da cidadania. Mas estes meios eletrônicos que fizeram irromper as massas populares na esfera pública foram deslocando o desempenho da cidadania em direção às práticas de consumo. Foram estabelecidas outras maneiras de se informar, de entender as comunidades a que se pertence, de conceber e exercer os direitos. Desiludidos com as burocracias estatais, partidárias e sindicais, o público recorre à rádio e à televisão para conseguir o que as instituições cidadãs não proporcionam: serviços, justiça, reparações ou simples atenção (CANCLINI, 2008, p. 38-39).

Alcançando grande relevância no dia a dia dos cidadãos, o impacto do rádio, cinema e TV foi, e ainda é, fator considerável para a evolução das percepções sobre cidadania, e da evidenciação do espaço de manifestação desta. Canclini (2008, p.129), analisando o século $\mathrm{XX}$, afirma que "o rádio e o cinema contribuíram na primeira metade deste século para organizar os relatos da identidade e o sentido de cidadania nas sociedades nacionais". Fazendo uma referência ao papel deslocador das mídias em relação à cooptação dos indivíduos que deixaram suas atividades interpessoais nas ruas, locais onde se conversava e significava os assuntos da polis, e partiram para frente de monitores que lhes traziam préprontas essa significação, Tuzzo (2014) afirma que,

Sobre isso, podemos então pensar que a relação de cidadania foi transferida das ruas, da cidade para uma relação existencial transmitida pelos meios de comunicação, o que nos faz refletir sobre a possibilidade do reconhecimento que seja ser cidadão ser recriado pela mídia, que redefine o conceito e reapropria de valores o cidadão atual. (TUZZO, 2014, p.166)

A autora ainda reforça que o papel da mídia na ressignificação da cidadania passa pela representação do real, projetada pelos meios de comunicação que servirão como base para o entendimento e significação dos cidadãos-espectadores. $\mathrm{O}$ discurso midiático passa então a legitimar o cidadão, diferenciando-o, subjetivamente, do não-cidadão, papel que até então era concernente ao Estado e aos próprios cidadãos. Os autores Durán Barba y Nieto (2006, p.91)

Comun. \& Inf., Goiânia, GO, v. 18, n. 02, p. 163-179, jul./dez. 2015

Caderno Casadinho Procad UFG-UFRJ 


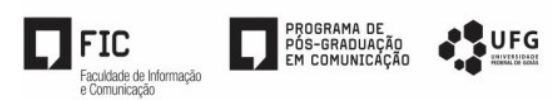

ao analisar o uso político dos meios de comunicação disseram: “o rádio levou a voz através do espaço a uma velocidade incrível. Os líderes falavam em qualquer lugar e eram escutados em territórios cada vez maiores. Muitíssima gente adentrou à política através do ouvido" ${ }^{4}$. Os pesquisadores equatorianos ainda reforçam que, após o rádio, com o advento da televisão, as formas de projeção das imagens do real para a significação por parte dos espectadores alteraram sua compreensão do mundo. "A televisão influi de modo determinante na forma como os seres humanos estruturam a realidade" ${ }^{2}$. (DURÁN BARBA y NIETO, 2006, p.93). Ampliando suas análises, os autores acreditam que o uso generalizado da televisão, dando acesso aos conteúdos e informações que antes eram restritos às elites, democratiza essas informações e fortalece a independência dos cidadãos políticos além de diminuir a fenda entre os mais e os menos informados.

Para além do viés positivo, apontado por Durán Barba y Nieto, é importante observar que surge um novo momento no qual se somam diferentes formas de reconhecimento e legitimação da cidadania, agora não mais perpassando apenas as garantias do Estado ou o reconhecimento daqueles que se consideram cidadãos sobre os que, por sua condição sócio histórica, política e econômica, não conseguem afirmar sua própria cidadania. Tal situação pode, ainda que resolva em partes a questão da desinformação, gerar abissais diferenças subjetivas num primeiro momento, mas que se desdobram radicalmente em questões práticas e tangíveis nas sociedades atuais -, que impactam nas formas e atuações dos indivíduos dentro da polis.

Tuzzo (2014) afirma que o discurso midiático é feito para o subcidadão, pois retrata sempre uma cidadania ausente, incompleta. Ao evidenciar uma cidadania precária, apresentando um distanciamento entre o que deveria estar de posse de todos, mas está sob a posse de alguns, a autora afirma que o discurso midiático desnuda a perspectiva de que há outros critérios a serem analisados para a concessão da cidadania plena, além daqueles ora citados. O discurso midiatizado consegue ganhar mais espaço entre os distintos públicos que configuram as massas de indivíduos, do que as definições acadêmicas que ficam restritas aos poucos que a elas tem acesso. Queda-se assim o discurso midiático com potencial força opressora, dissuasora e/ou estimulante e engajadora sobre aqueles distantes do conhecimento

\footnotetext{
${ }^{4}$ La radio llevó la voz a través del espacio a una velocidad increíble. Los líderes hablaban em cualquier sitio y eran escuchados em territorios cada vez mayores. Muichíssima gente se incorporó a la política a través del oído. (Tradução livre do autor)

${ }^{5}$ La televisión influye de manera determinante en la forma en que los seres humanos estructuran la realidade. (Tradução livre do autor)
}

Comun. \& Inf., Goiânia, GO, v. 18, n. 02, p. 163-179, jul./dez. 2015

Caderno Casadinho Procad UFG-UFRJ 
científico. Observando grande parte das representações midiáticas sobre cidadania, segundo Tuzzo (2014), pode-se verificar que:

O cidadão é aquele que está na sociedade economicamente privilegiada e pode pagar pela cidadania, comprando saúde, educação, segurança, lazer, por exemplo, ou seja, a cidadania é comprada, é privada, disponível e acessível para quem pode pagar por ela. Assim, cidadania tem a ver com o privado e a busca da cidadania tem a ver com o que é público. Cidadania é a plenitude de existência do rico e a busca constante do pobre (TUZZO, 2014, p.177).

Amplificada pela mídia, a noção de que a cidadania não é para todos, como então acreditar - e neste trabalho já evidenciamos essa impossibilidade - que todos trabalharão para a construção de uma sociedade melhor, que reivindicarão seus direitos e corresponderão aos deveres que lhes cabem? Como já dito, quem não é reconhecido como cidadão acaba também não se reconhecendo como tal. É possível verificar essa situação nos comportamentos interpessoais, nas relações com o espaço público, com o processo político-eleitoral, em suma, vê-se que a ausência de auto identificação do indivíduo enquanto cidadão acaba por afastá-lo ainda mais de sua cidadania. Sonegado em seus direitos, alheio aos deveres, esse não cidadão ou, segundo Tuzzo (2014), "subcidadão”, não é capaz de reconhecer seu espaço na polis, não contempla nas ruas e espaços públicos um lugar que lhe possibilita a manifestação política, de luta em prol do resgate de sua identidade, de sua cidadania.

\section{AS TICS E SUAS POSSIBILIDADES}

Quando se olha para o processo evolutivo das sociedades, intrinsicamente ligado à evolução das tecnologias da informação e comunicação (TICs), percebe-se que a maior proximidade entre os indivíduos e a informação sempre resultou em mudanças de comportamento e participação dentro da polis.

É impossível pensar na evolução e crescimento das cidades sem levar em consideração o desenvolvimento dos meios de comunicação. A própria noção de pertencimento, sentimento básico para a auto percepção cidadã, segundo Carvalho (2002), foi e é significada e ressignificada constantemente pelos meios de comunicação.

Sem acesso de modo autônomo ao conteúdo disseminado pela mídia de massa sobre si, suas carências e demandas, sem ambiente e reconhecimento nos espaços públicos que também não lhe pertenciam, muitos indivíduos começaram a migrar para um contexto virtual onde os limites, aparentemente, não lhes eram tão restritivos como os do mundo "real". Ainda 
que não seja possível tratar o ambiente virtual como igualitário, em nível de acesso, é possível enxergá-lo como possível espaço livre para manifestações, questionamentos, ressignificações, aprendizado e construção, talvez, de identidades. Santos (2011, p.183) afirma que,

As inferências acima nos impelem à insistência em repensar os espaços públicos da esfera da sociedade massiva em contraposição às espacialidades da era virtual, como novas esferas de emancipação política e de democratização da sociedade (SANTOS, 2011, p.183).

O autor ainda acredita que a ampliação da estrutura comunicativa, dos dispositivos capazes de amplificar as vozes do maior número de pessoas, engajando-as no debate sobre as questões públicas, oportunizará uma evolução do processo democrático, uma emancipação da sociedade. Porém, Santos (2011) destaca que não apenas pela evolução das tecnologias, mas fundamentalmente pelo desejo do indivíduo em participar desta, é que será capaz de se produzir os efeitos esperados no processo de evolução social e apropriação da cidadania. Como apresentado nesta pesquisa, e referenciado pelos autores ora apresentados, o processo reconhecimento-pertença que confere significação à cidadania hodiernamente é indissociável da relação indivíduo-meios de comunicação.

A reflexão atual sobre a identidade e a cidadania precisa situar-se em relação a vários suportes culturais, e não só em relação ao folclore ou à discursividade política, como ocorreu nos nacionalismos do século XIX e princípios do XX. Deve também levar em conta a diversidade de repertórios artísticos e de meios de comunicação que contribuem para a reelaboração das identidades (CANCLINI, 2008, p.136).

Há algum tempo pesquisas vem sendo realizadas sobre o papel das novas tecnologias da informação e comunicação (TICs) no desenvolvimento das sociedades e de sua apropriação da cidadania. Essa apropriação se relaciona com uma cidadania ativa, dentro da perspectiva de Cortina (2005), que envolve participação política e social motivadas pelo sentimento de pertença e legitimadas pelo reconhecimento obtido dos demais cidadãos. Ainda sobre o que foi apresentado neste texto, o papel dos meios de comunicação é de extrema relevância no processo de significação, ressignificação, construção e negação da imagem do cidadão pleno e de suas possibilidades de atuação dentro da polis.

De posse do método de pesquisa bibliográfica buscou-se entender a maneira com que a internet e suas redes e mídias sociais tem impactado nas relações indivíduo-indivíduo, indivíduo-Estado e Estado-indivíduo - nas esferas sociais, econômicas e políticas - a fím de compreender possíveis mudanças de hábitos, potencialidades de engajamento, 
questionamento, proposição e, efetivamente, participação do cidadão nas decisões que lhe impactam o cotidiano. No momento em que paradigmas tangenciadores da relação real/virtual são questionados, ir em direção ao entendimento da forma de uso que o internauta faz das TICs na busca por conquistar, manter e/ou ampliar o seu status de cidadão apresenta-se de grande relevância para aqueles que pretendem alcançar maior entendimento da sociedade à qual pertencem.

Atualmente notamos a internet mais acessível - no tocante ao desenvolvimento tecnológico, acesso móvel por smartphones, tablets e demais equipamentos eletrônicos - e capaz de conectar pessoas e instituições, abrindo canais de informação e comunicação que oportunizam interações e atuam no processo de percepção e apropriação da cidadania. Hoje os indivíduos partilham conteúdos atinentes ao tema e agora tem possiblidades de comentar, questionar e/ou reivindicar sua situação dentro da cidade. Sobre isso Nery e Temer (2009) afirmam que,

Mais do que em qualquer outra época, as possibilidades técnicas têm gerado dispositivos de comunicação com o potencial de transformar o modo como o homem se relaciona consigo mesmo, com seu trabalho e com o mundo que o rodeia. A emergência desses novos dispositivos e tecnologias de comunicação e a multiplicidade de possibilidades que eles oferecem têm proporcionado o surgimento de novos comportamentos, novas formas de interação e novos processos de sociabilidade (NERY; TEMER, 2009, p.118).

Essa característica bilateral da internet tem afetado também os meios tradicionais de comunicação, fazendo com que deixem de ser canais unilaterais de disseminação de conteúdo e busquem estreitar relacionamento com seus espectadores, gerando níveis ou sensações de interatividade, neste caso usando a própria internet como ferramenta complementar de comunicação.

Com as transformações dos canais de comunicação, seja pela cooptação da internet pelos veículos tradicionais ou pela evolução tecnológica da própria internet e seus gadgets, devemos considerar que existem também constantes ressignificações dos conteúdos e meios envolvidos nos processos comunicacionais. Enxergar a internet como um novo meio é aceitar que, associada ou não aos meios tradicionais, a sua utilização influencia na significação dos conteúdos que veicula, incluindo aqueles sobre cidadania. Temos então, seguindo a proposta de McLuhan (2006), vários veículos interagindo para a formação de um significado na mente dos indivíduos. 
A acessibilidade aos conteúdos relativos à política, direitos sociais e civis, economia, entretenimento, dentre outros, oportunizada pela internet, tornou-se um novo modelo na formação dos referenciais utilizados pelos indivíduos em sua significação do mundo. Segundo Recuero (2009), os paradigmas que envolvem o fenômeno da internet geram impacto nas relações interpessoais e sociais cotidianas. Os atores - elementos que interagem pelas redes e suas conexões, através de relações, interações e, também, laços sociais que são formados dentro da rede, modificam a realidade offline.

Como dito anteriormente a ampliação dos meios de comunicação produziu ao longo da história, se não todas, as maiores modificações sociais mundiais, influenciando questões políticas e religiosas que praticamente mantiveram e moldaram os caminhos da humanidade até aqui. A comunicação chega ao século XXI tendo como suporte midiático a rede mundial de computadores, que se apropriou e tem direcionado praticamente toda evolução tecnológica mundial. Segundo Wolton (2012),

Três palavras são essenciais para compreender o sucesso das novas tecnologias: autonomia, domínio e velocidade. Cada um pode agir, sem intermediário, quando bem quiser, sem filtro nem hierarquia e, ainda mais, em tempo real (WOLTON, 2012, p.83).

Como vemos durante toda história da humanidade, a cada aproximação ocorrida entre os indivíduos e a informação, veiculada por meios diversos de disseminação, houve também algum ganho em nível de cidadania para estes indivíduos. Como afirma Castells (2006):

A sociedade é que dá forma à tecnologia de acordo com as necessidades, valores e interesses das pessoas que utilizam as tecnologias. Além disso, as tecnologias de comunicação e informação são particularmente sensíveis aos efeitos dos usos sociais da própria tecnologia (CASTELLS, 2006, p. 17).

Nesta perspectiva instrumental das TICs, temos que os grupos sociais ao dominarem as tecnologias fazem uso das mesmas de acordo com seu contexto sociocultural. Ainda sem observar questões externas ao indivíduo, recebemos de Wolton (2012) um atrelamento do uso das ferramentas de comunicação - aqui uma visão técnica das tecnologias da informação e comunicação - à busca por autonomia e liberdade por parte do sujeito que as utiliza. Diz o autor:

As dimensões psicológicas são de fato essenciais na atração pelas novas tecnologias, pois elas vêm ao encontro do profundo movimento de individualização de nossa sociedade. Elas simbolizam a liberdade e a capacidade de dominar o tempo e o espaço, um pouco como os automóveis nos anos 30 (WOLTON, 2012, p. 83). 
Essa busca por algum nível de empoderamento dentro do contexto social, seja através da consecução de informação, seja pela própria produção de conteúdos carregados de opiniões, constatações e contestações assemelha-se bastante à busca pela plenitude da cidadania, a qual reconhecerá os direitos daqueles que lhe possuem.

E é por isso que as novas tecnologias adquiriram uma dimensão social; elas representam um pouco "uma nova chance" para todos aqueles que perderam a primeira. As novas tecnologias são, como uma figura de emancipação individual, "uma nova fronteira" (WOLTON, 2012, p. 83-84).

No entanto, devemos ressaltar que no Brasil o acesso a essas novas tecnologias não está garantido a todos. A "nova chance" ainda não está ao alcance dos cidadãos de maneira equânime. $\mathrm{O}$ acesso à internet é ainda dificultado por questões de disponibilidade técnica, ausência de recurso financeiro e até mesmo por questões políticas e educacionais. A evolução das tecnologias de informação e comunicação, com todo seu potencial dispersor de conteúdos, não garante a existência do novo e "conectado" cidadão. Mesmo que autores como Wolton (2012, p.83) afirmem que a internet é "um mundo aberto e acessível a todos, e que finalmente dá uma chance a cada um, quais sejam seu itinerário profissional e seus diplomas”, nossa realidade não é bem essa.

Tendo acesso ao relatório da Pesquisa Brasileira de Mídia 20156 , realizada pela SECOM da Presidência da República, constatamos que 51\% da população brasileira ainda não utiliza a internet. Esse dado é corroborado pela afirmação de que,

No Brasil, as características sociodemográficas da população têm um grande impacto no uso da internet, principalmente se comparada aos outros meios de comunicação. Renda e escolaridade criam um hiato digital entre quem é um cidadão conectado e quem não é. Já os elementos geracionais ou etários mostram que os jovens são usuários mais intensos das novas mídias (BRASIL, 2015, p.49).

As questões que dificultam ou excluem tão significativa parcela da população merecem atenção. Seja por falta de habilidade, percepção de necessidade ou custos, dados também apontados na pesquisa, a não adesão ao novo modal comunicacional tende a isolar cada vez mais essas pessoas. À medida que a internet vai ganhando espaço dentro das relações pessoais e sociais, seu papel na ressignificação do mundo, das coisas que impactam na vida dos cidadãos também vai se ampliando. É possível que cheguemos a um ponto onde as ferramentas que poderiam estreitar distâncias abrirão uma fenda abissal entre grandes

\footnotetext{
${ }^{6}$ Disponível em: http://www.secom.gov.br/atuacao/pesquisa/lista-de-pesquisas-quantitativas-e-qualitativas-de-contratosatuais/pesquisa-brasileira-de-midia-pbm-2015.pdf
} 
parcelas da sociedade, dificultando ainda mais a possibilidade de uma cidadania horizontalizada e integralizadora.

Segundo Durán Barba e Santiago (2006, p.100): "Usando a rede, um cidadão moderadamente treinado pode obter toda a informação que queira, sobre qualquer tema", desta forma torna-se premente que se invista em acessibilidade para esses meios. Não apenas no quesito de cobertura territorial, mas na melhoria das interfaces que podem estar, também, dificultando que pessoas com menor habilidade e conhecimentos, linguísticos e de tecnologia, utilizem as ferramentas que servem de porta de entrada para o mundo digital.

Sendo assim, é possível pensar que a utilização das TICs possa permitir aos indivíduos o contato com temas relativos a direitos e deveres, bem como o debate sobre os mesmos, capacitando-os à apropriação destes direitos e do gozo pleno da cidadania. No entanto não podemos ignorar que alguns grupos já estejam utilizando as redes para, de alguma forma, manter o poder conquistado através do domínio dos meios tradicionais de comunicação. Grupos midiáticos e políticos tentam iludir muitos usuários das TICs dando-lhes uma pseudo noção de participação, democracia e cidadania. Sobre isso Levy (1999) escreveu,

A respeito desse último ponto, que muitas vezes geral mal-entendidos, esclareço que a difusão de propagandas governamentais sobre a rede, o anúncio dos endereços eletrônicos dos líderes políticos, ou a organização de referendos pela internet nada mais são do que caricaturas de democracia eletrônica. A verdadeira democracia eletrônica consiste em encorajar, tanto quanto possível - graças às possibilidades de comunicação interativa e coletiva oferecidas pelo ciberespaço -, a expressão e a elaboração dos problemas da cidade pelos próprios cidadãos, a auto-organização das comunidades locais, a participação nas deliberações por parte dos grupos diretamente afetados pelas decisões, a transparência das políticas públicas e sua avaliação pelos cidadãos (LEVY, 1999, p.186).

A exposição do autor desperta nossa atenção para possíveis atuações dos tradicionais grupos de poder dentro da internet, do ciberespaço, que obviamente visam à manutenção do status quo, à disseminação do ilusório sentimento de pertença, da falsa participação política e cidadã, que por séculos tem subjugado grandes parcelas da sociedade.

Se a simples existência de direitos, per se, não garante sua apropriação por todos de forma igualitária, poderá ser o conhecimento destes que interferirá no comportamento dos indivíduosquando se sentirem subjugados. A internet pode oportunizar uma aproximação

\footnotetext{
${ }^{7}$ usando la red, un ciudadano medianamente entrenado puede conseguir toda la información que quiera, acerca de cualquer tema. (Tradução livre do autor)
}

Comun. \& Inf., Goiânia, GO, v. 18, n. 02, p. 163-179, jul./dez. 2015

Caderno Casadinho Procad UFG-UFRJ 
entre o indivíduo e seus direitos, dando-lhe ferramentas para conhecê-los, reivindicá-los e denunciar quando estes forem suprimidos ou desrespeitados.

Considerando o que foi exposto neste trabalho, resta-nos abordar também um ponto crucial para a concessão de voz ao cidadão: a forma de educá-lo para o uso das ferramentas ora disponíveis. O próprio Wolton (2012), que em certo momento atribui liberdade e acessibilidade total ao usuário das redes de informação e comunicação digitais, salienta que “o acesso a 'toda e qualquer informação' não substitui a competência prévia, para saber qual informação procurar e que uso fazer dessa”. (WOLTON, 2012, p. 85)

É fato que a tecnologia está presente em nosso cotidiano, se não ainda de modo horizontalizado, possivelmente caminhando nesta direção. Porém, corremos o risco de vermos um déjà vú da história dos meios de comunicação, quando a produção de impressos se via limitada pela ausência de um mercado leitor em dinâmico crescimento. Em breve, se já não chegamos a isso, teremos muito mais tecnologia disponível do que pessoas em condições de usufruí-las. Assim, continuaremos experimentando um nível anacrônico de cidadania enquanto vivenciamos um mundo futurista e tecnológico.

A comunicação desenvolveu-se socialmente à medida que seus suportes também se desenvolveram. O próprio aparelho fonador humano alterou-se ${ }^{8}$ devido ao uso cada vez mais intenso, constante e variado motivado pelo crescente processo interacional advindo das formações de coletividades, de sociedades e suas instalações em cidades. Desta forma é possível acreditar que há uma relação de aprendizado e desenvolvimento a preceder o empoderamento oportunizado pela evolução dos mecanismos e processos comunicacionais. Fatalmente a evolução trazida pela comunicação também é refletida na própria sociedade, alterando e ressignificando suas crenças, atitudes, formas de convivência e interação.

Pierre Lévy (1999) acredita que a cibercultura ${ }^{9}$ é uma inovação das elaborações culturais da humanidade, calcada na interação e ressignificação dos processos comunicacionais produzidos e reproduzidos em larga escala por comunidades virtuais e globais. O autor define o local de produção da cibercultura como ciberespaço ${ }^{10}$ e reconhece

\footnotetext{
${ }^{8}$ Como o Homem fala. Disponível em: http://super.abril.com.br/ciencia/como-o-homem-fala. Acesso em $10 / 10 / 15$

${ }^{9}$ Um tipo distinto de cultura que se desenvolveu juntamente com as tecnologias de comunicação e informação digital, especialmente na internet; sistema de significado aprendido, que inclui crenças, valores, práticas, papeis, e línguas, que ajuda a direcionar e organizar determinadas formações sociais online ou relacionadas à tecnologia. (KOZINETS, 2014, p. 176)

${ }^{10} \mathrm{O}$ termo especifica não apenas a infra-estrutura material da comunicação digital, mas também o universo oceânico de informações que ela abriga, assim como os seres humanos que navegam e alimentam esse universo. (LÉVY, 1999, p.17)
}

Comun. \& Inf., Goiânia, GO, v. 18, n. 02, p. 163-179, jul./dez. 2015 
seu impacto nas artes, na necessidade de revisão dos processos educacionais, a fim de permitir que lhe assimilem plenamente, bem como impactos na forma de pensar as cidades e nas filosofias políticas que regem as sociedades. Acima de tudo, Lévy (1999, p. 29) acredita na “inteligência coletiva" como sendo a força motriz para o desenvolvimento desta nova cultura.

Essa inteligência coletiva de que fala Lévy (1999) pode ser entendida como a produção intelectual e técnica dos próprios usuários da internet, que se assomam em comunidades online ${ }^{11}$ na busca pelo desenvolvimento constante da rede e das interações através desta, o que acaba por retroalimentar constantemente o processo comunicacional online produzindo uma cultura ciberespacial que, inegavelmente, interfere e atua também nas culturas urbanas, principalmente, off-line.

\section{CONSIDERAÇÕES FINAIS}

Os homens construíram as cidades motivados por interesses ligados à própria sobrevivência, num primeiro momento. Para que esta forma de convivência coletiva pudesse perdurar foi necessário que sistemas normativos surgissem. Podemos considerar que assim surgiram os direitos e deveres que, segundo autores citados neste trabalho, parametrizariam a conduta dos cidadãos, dos viventes na polis.

Porém a divisão entre direitos e deveres não se deu de modo igualitário em nenhum momento que se tem registro na história. Muitas vezes a falta de conhecimento sobre quais seriam seus direitos, fez com que vários cidadãos sobrevivessem apenas para o cumprimento de seus deveres. Fato que ainda hoje se pode notar em algumas localidades.

A evolução dos meios de comunicação e informação além de otimizar as relações daqueles que primeiro tiveram acesso a eles, também trouxe em seu bojo a possibilidade de dispersão de conteúdos para aqueles que até então estavam alheios ao que ocorria fora de seus pequenos círculos de convívio, onde eram facilmente manipulados e subjugados por força, dogma e ausência de outras referências que não as fornecidas por aqueles que lhes mantinham na ignorância.

\footnotetext{
${ }^{11}$ Uma comunidade manifesta por meio de qualquer forma de comunicação mediada por computador; um grupo de pessoas que se comunicam e compartilham interação social e laços sociais por meio da internet ou de outra comunicação mediada por computador, como correio eletrônico, listas, fóruns, grupos de discussão, websites de compartilhamento de fotos, blogs, mundos virtuais ou websites de redes sociais; os níveis de participação variam amplamente, desde assinantes em grande parte passivos até organizadores altamente envolvidos. (KOZINETS, 2014, p. 176)
}

Comun. \& Inf., Goiânia, GO, v. 18, n. 02, p. 163-179, jul./dez. 2015

Caderno Casadinho Procad UFG-UFRJ 
A evolução dos meios de comunicação promoveu profundas alterações no contexto social das cidades impactadas pelas mídias. O surgimento das mídias radiofônica e televisiva atuou, é possível pensar, como um grande libertador daqueles que não eram alfabetizados e por isso estavam alheios aos conteúdos informacionais, o que fatalmente transformou completamente a forma como estas pessoas significavam o mundo e sua própria existência.

Atualmente estamos envoltos em nuvens de informação, em novas plataformas de comunicação e interação que surgem diariamente através da internet. Com uma velocidade impossível de ser comparada a outras etapas do processo evolutivo dos meios de comunicação, tanto a tecnologia que a rede mundial de computadores carrega, como as formas de uso, produção e reprodução de conteúdo tem impactado indivíduos e instituições de todos os matizes.

Com potencial para auxiliar os indivíduos na apropriação de sua cidadania, que ainda se encontra distante de ser plena e igualitária para todos, as novas tecnologias precisam ser dominadas, ensinadas e disseminadas amplamente. Porém, é importante lembrar que o mau uso destas TICs pode influenciar fortemente na ampliação das diferenças, das distâncias entre os indivíduos, na negação da cidadania àqueles que não aderirem, seja por qual motivo for, à nova realidade comunicacional que se apresenta.

Ponderando sobre todo o exposto nas páginas precedentes, podemos concluir que apenas a evolução dos processos educacionais (em forma, métodos e conteúdos) poderá promover uma sociedade mais capacitada para reclamar, exercer e proteger sua própria cidadania, utilizando para isso toda tecnologia disponível.

\section{REFERÊNCIAS}

BRASIL. Presidência da República. Secretaria de Comunicação Social. Pesquisa brasileira de mídia 2015: hábitos de consumo de mídia pela população brasileira. Brasília : Secom, 2014. Disponível em: $<$ http://www.secom.gov.br/atuacao/pesquisa/lista-de-pesquisas-quantitativas-e-qualitativas-decontratos-atuais/pesquisa-brasileira-de-midia-pbm-2015.pdf $>$. Acesso em: 10/09/15.

CANCLINI, N. G. Consumidores e cidadãos. 7. ed. Rio de Janeiro: Editora URFJ, 2008.

CARVAlhO, J. M. Cidadania no Brasil: o longo caminho. 3. ed. São Paulo: Civilização Brasileira, 2002.

CASTEllS, M.; CARDOSO, G. (Orgs.). A Sociedade em rede: do conhecimento à ação política. Portugal: Imprensa nacional; Casa da moeda, 2006.

CORTINA, Adela. Cidadãos do mundo: uma teoria da cidadania. São Paulo: Edições Loyola, 2005. 
DURÁN BARBA, J.; SANTIAGO, N. Mujer, sexualidade, internet y política: los nuevos electores latinoamericanos. México: FCE, 2006.

LEVY, P. Cibercultura. São Paulo: Ed. 34, 1999.

MARSHALL, T. H. Cidadania, classe social e status. Rio de Janeiro: ZAHAR Editores, 1967.

MCLUHAN, M. Os meios de comunicação como extensões do homem. 18. ed. São Paulo: Cultrix, 2006.

MEKSENAS, P. Cidadania, poder e comunicação. 2. ed. São Paulo: Cortez, 2002.

NERY, V. C. A.; TEMER, A. C. R. P. Para entender as teorias da comunicação. EDUFU: Uberlândia, 2009.

RECUERO, R. Redes sociais na internet. Porto Alegre: Sulina, 2009.

RIBEIRO, R. J. Hobbes: o medo e a esperança. In. WEFFORT, F. C. (Org.). Os clássicos da política. 14. ed. São Paulo: Ática, 2006.

SANTOS, Goiamérico Felício Carneiro dos. Ágora virtual: Espaços de Emancipação Política, ou Lugares de Consumo?. In: BONILHA, Kátia Raquel; SATLER, Lara Lima (Org.). Século XXI: a Publicidade sem fronteiras? Goiânia: Editora Puc Goiás, 2011. p. 175-192.

WOLTON, D. Internet, e depois? Uma teoria crítica das novas mídias. 3. ed. Porto Alegre: Sulina, 2012. 